'B Orive, ${ }^{2} \mathrm{~J}$ Montiano, ${ }^{2} \mathrm{C}$ Salado, ${ }^{3} \mathrm{~A}$ Torrents. ${ }^{1}$ Pediatric Nephrology; ${ }^{2}$ Pediatrics, Hospital Universitario de Álava, Vitoria; ${ }^{3} G e n e t i c s$, Reference Laboratory, Barcelona, Spain

Introduction Gitelman syndrome is an inheredited tubular disorder characterized by metabolic alkalosis, hypokaliemia and hypomagnesemia of renal origin and hypocalciuria. The majority of patients with Gitelman syndrome carry inactivating mutations in the SLC 12A3 gene encoding the sodium- chloride cotransporter located in the distal convoluted tubule. The purpose of this report is to describe a new mutation of the SLC12A3 gene in a gypsy boy, mutation of ancient origin that would be specific in this ethnic group and spread throughout Europe.

Case Report A 5 years old male children of Roma origin (Gypsy) was referred to our hospital because asthenia, muscle weakness and hypokaliemia. Both parents are healthy, non consanguineous with normal serum potassium. There were no other family members affected. Relevant biochemical data at diagnosis was: Serum: $\mathrm{pH}$ 7.52, bicarbonate $31 \mathrm{mmol} / \mathrm{L}$, potassium $2 \mathrm{mEq} / \mathrm{L}$, sodium 136 $\mathrm{mEq} / \mathrm{L}$, chloride $97 \mathrm{mEq} / \mathrm{L}$, magnesium $1.6 \mathrm{mg} / \mathrm{dl}$, creatinine $0.4 \mathrm{mg} /$ dl, calcium 9 mg/dl. Plasma Renin Activity 13.3 ng/ml/h, Aldosterone $138 \mathrm{pg} / \mathrm{ml}$.

Urinary potassium $51 \mathrm{mEq} / \mathrm{L}$, calcium/creatinine ratio 0.12 ; Potassium fraccional excretion $20.4 \%$, magnesium fractional excretion $5.9 \%$. Renal ultrasonography and blood pressure was normal.

Genetic study was performed: the patient was homozygous for splice site mutation guanidine to thymine in the first position of intron 9 of SLC12A3 gene (intron $9+1 \mathrm{G}>\mathrm{T}$ ).

Conclusion This finding will facilitate the identification of the genetic defect in further cases of Gitelman syndrome among the gypsy population. This patients exhibit muscle syntoms and asthenia althroug the disease is not particulary severe in this ethnic group.

\section{A BOY WITH HYPERKALEMIA AND HYPERTENSION WITHOUT FAMILY HISTORY: STILL PSEUDOHYPOALDESTERONISM (GORDON SYNDROME)?}

doi:10.1136/archdischild-2012-302724.1213

'RA Hollander, ${ }^{1} \mathrm{D}$ Trouet, ${ }^{2} \mathrm{G}$ Mortier. ${ }^{1}$ Pediatric Nephrology; ${ }^{2}$ Medical Genetics, Antwerp University Hospital, Edegem (Antwerp), Belgium

Background and Aims We report a 6-year-old boy presenting with macroscopic hematuria, hyperkalemia and hyperfosfatemia.

Results A 6-year-old boy presented to our outpatient clinic with hematuria. No clinical abnormalities were found, besides borderline hypertension of $120 / 60 \mathrm{mmHg}$ (P95 adjusted for height and age 100/57). Laboratory testing revealed a serum potassium of 8.6 $\mathrm{mmol} / \mathrm{l}$ and a phosphate of $6.2 \mathrm{mg} / \mathrm{dl}$. During admission hyperkalemia appeared refractory to standard treatment with furosemide, salbutamol and alkalinisation. Prompt reduction of hyperkalemia was observed after a trial with hydrochlorothiazide, suggesting the diagnosis of pseudohypoaldesteronism. Further testing revealed a high aldosteron of $537 \mathrm{pg} / \mathrm{ml}$. Familial history was negative but still a suspicion of pseudohypoaldosteronim remained, so genetic testing was performed. A de novo splice site mutation was found in the CUL3-gene (c.1377+1G>A) leading to a skipping of exon 9 .

Conclusions We present an atypical presentation of Gordon syndrome (familial hyperkalemic hypertension) due to a de novo splice mutation. The clinician should be aware of this possibility when facing a child with high serum potassium.

\section{SEVERE RICKETS AND HYPOKALEMIC FLACCID PARALYSIS DUE TO DISTAL RENAL TUBULAR ACIDOSIS (DRTA) IN A 4-YEAR-OLD GIRL}

JD Martinez-Pajares, 0 Diaz-Morales, J Trigo-Moreno, JC Ramos-Diaz, M MirandaValdivieso, E Fernandez-Gomez. UGC Pediatria, Hospital Comarcal de Antequera, Antequera, Spain

Background dRTA is a tubulopathy characterized by metabolic acidosis with normal anion gap secondary to a defective secretion of $\mathrm{H}+$ ions by the collecting tubule. This anomaly leads to an inability to acidify the urine during systemic acidemia. There are more than 50 different mutations, with an autosomal recessive or dominant pattern of transmission. Clinical features usually appear from two years of age as vomiting, dehydration and failure to thrive, although the first signs may be present from the first weeks of life. In recessive forms can be associated with sensorineural deafness. The prognosis is favorable if alkali replacement is performed properly. However, urolithiasis, nephrocalcinosis and chronic renal failure may appear if the diagnosis is delayed or the treatment is inadequate.

Case Report We report a 4-year-old Morrocan girl with a history from the first months of life characterized by failure-to-thrive, hyporexia, polydipsia and polyuria, and delayed motor function. In recent months she was unable to ambulate due to progressive muscle weakness, especially of the lower limbs. Physical findings included a severe weight and height delay, signs of severe malnutrition and rickets, and tachypnea. Laboratory findings were consistent with distal renal tubular acidosis (metabolic acidosis with normal anion gap, severe hypokaliemia, hypophosphatemia, mild hypocalcemia, and hypouricemia, with urinary $\mathrm{pH}>6$ and positive urinary gap). Also, bilateral renal nephrocalcinosis was found. Alkali replacement was able to correct the electrolytic abnormalities and promote catch-up.

Comments dRTA must be suspected in the presence of the clinical and laboratory findinds reported.

\section{REFERENCE VALUES OF SERUM CYSTATIN C IN VERY LOW BIRTH WEIGHT PREMATURE INFANTS}

doi:10.1136/archdischild-2012-302724.1215

${ }^{1} \mathrm{G}$ Demirel, ${ }^{1} \mathrm{HH}$ Celik, 'FE Canpolat, ${ }^{2} \mathrm{O}$ Erdeve, ${ }^{3} \mathrm{Z}$ Biyikli, 1,4 $\mathrm{U}$ Dilmen. 'Neonatology; ${ }^{2} Z$ Zekai Tahir Burak Maternity and Teaching Hospital; ${ }^{3}$ Biostatistics, Ankara University; ${ }^{4}$ Pediatrics, Yildirim Beyazit University, Faculty of Medicine, Ankara, Turkey

Background and Aims To determine reference values for cystatin $\mathrm{C}(\mathrm{Cys} \mathrm{C})$ and its correlation with creatinine (Cr), gestational age, birth weight and maternal $\mathrm{Cr}$ status in very low birth weight (VLBW) preterm infants.

Aims The study included 113 VLBW premature infants $(<1500 \mathrm{~g})$ of $\leq 32$ gestational week.

Results The mean level of CysC was $1.77 \pm 0.38 \mathrm{mg} / \mathrm{L}$ on day 1 and $1.61 \pm 0.37 \mathrm{mg} / \mathrm{L}$ on day 3 , and the decrease was statistically significant. There was a significant correlation only between maternal $\mathrm{Cr}$ and first-day $\mathrm{Cr}$ values and negative correlations between $\mathrm{Cr}$ and gestational age and birth weight on third day. Creatinine was not correlated with CysC both on day 1 ( $r=-0.077, \mathrm{p}=0.417)$ and day $3(\mathrm{r}=0.132$, $\mathrm{p}=0.164)$. The reference values of Cys $C$ at birth are [median (3p-97p)] $1.8 \mathrm{mg} / \mathrm{dl}(0.8-2.2)$ for 24-26 weeks, $1.8 \mathrm{mg} / \mathrm{dl}(1.51-3.19)$ for 26-28 weeks, $1.8 \mathrm{mg} / \mathrm{dl}(0.65-2.48)$ for 28-30 weeks and $1.79 \mathrm{mg} / \mathrm{dl}(0.68$ 2.31) for 30-32 weeks and at 3rd days are $1.5 \mathrm{mg} / \mathrm{dl}(0.54-2.0)$ for 24-26 weeks, $1.61 \mathrm{mg} / \mathrm{dl}$ (1.1-3.4) for 26-28 weeks, $1.7 \mathrm{mg} / \mathrm{dl}(0.56$ 2.3) for 28-30 weeks and $1.6 \mathrm{mg} / \mathrm{dl}(0.92-2.21)$ for 30-32 weeks.

Conclusion CysC offer an important advantage in the measurement of renal functions independent from gestational age, birth weight and maternal Cr status in VLBW preterm infants.

\section{INTRAUTERINE GROWTH RESTRICTION AND DEVELOPMENTAL PROGRAMMING OF RENAL DISEASE}

doi:10.1136/archdischild-2012-302724.1216 
'S Vedovato, ${ }^{2} \mathrm{~S}$ Visentin, ${ }^{2} \mathrm{E}$ Cosmi, ${ }^{3} \mathrm{~F}$ Cavallin, ${ }^{4} \mathrm{M}$ Mion, ${ }^{4} \mathrm{M}$ Zaninotto, ${ }^{3} \mathrm{D}$ Trevisanuto, ${ }^{3} \mathrm{~V}$ Zanardo. ${ }^{1}$ Neonatal Intensive Care Unit, Department of Paediatrics, Hospital San Bortolo of Vicenza, Vicenza; ${ }^{2}$ Maternal Fetal Medicine Unit, Department of Woman and Child Health; ${ }^{3}$ Department of Pediatrics, University of Padua School of Medicine; ${ }^{4}$ Department of Laboratory Medicine, University-Hospital of Padova, Padova, Italy

Background and Aims Intrauterine growth restriction (IUGR) complicated by umbilical artery vasculopathy may have adverse effects on integrity and function of vascular endothelium and has been associated to atherosclerosis and to glomerulosclerosis risk in adulthood. Aortic intima media thickening, a preclinical sign of atherosclerosis, has been documented from intrauterine life, whereas the first signs of glomerulosclerosis have not been determined. So the aim of this study was to compare albuminuria/creatiniruria ratio (ACR) in IUGR and appropriate for gestational age (AGA) neonates.

Methods A prospective cohort study has been performed on 25 IUGR consecutive fetuses evaluated at Department of Woman and Child Health of Padua University between December 2009 and December 2010. They were considered IUGR if the estimated fetal weight (EFW) was below 10th percentile and the umbilical artery pulsatility index (PI) $>2$ standard deviations. Each IUGR newborn was matched with 2 controls AGA neonates, of the same gestational age \pm 1 week. They were considered AGA if the EFW was between 10th and 90th percentile. A urine sample was collected at 24-72 hours after birth for ACR determination.

Results Among the 25 IUGR fetuses enrolled, 2 were excluded because 1 had trisomy 21 and 1 renal agenesis. The remaining 23 were matched with 46 AGA newborns. ACR was significantly higher in IUGR compared to AGA newborns: median (IOR) 183.0 (113.6-264.7) vs 122.8 (72.5-191.9); $\mathrm{p}=0.04$.

Conclusions IUGR is associated with significantly greater albuminuria at birth. This may be an early marker of glomerulosclerosis, which leads to renal disease in adulthood.

\section{SENSORINEURAL HEARING LOSS AFTER NORMAL NEONATAL HEARING SCREENING IN VERY PRETERM INFANTS}

doi:10.1136/archdischild-2012-302724.1217

I van Noort-van der Spek, A Goedegebure, N Weisglas-Kuperus. Erasmus MC - Sophia Children's Hospital, Rotterdam, The Netherlands

Background and Aim To determine the prevalence of sensorineural hearing loss (SNHL) measured by auditory brainstem response $(\mathrm{ABR})$ at 2 years of corrected age in very preterm (VPT) infants with normal neonatal hearing screening (NHS).

Methods 85 VPT infants (gestational age $<32$ weeks, birth weight $<1850$ grams), born between October 2008 and February 2010, underwent NHS by automated auditory brainstem response (AABR) shortly after birth and $A B R$ at 2 years of corrected age. The frequency of SNHL in VPT infants with bilateral pass AABR was analyzed. SNHL was estimated from the ABR responses and defined as a hearing loss $>20 \mathrm{~dB}$ for at least one ear, after correction for possible conductive hearing loss. Univariate analyses were performed to identify risk factors associated with SNHL.

Results Bilateral pass AABR shortly after birth was found in 81 (95\%) VPT infants. In spite of bilateral pass AABR, 23 (29\%) out of 78 VPT infants had hearing loss, defined as an estimated hearing loss $>20 \mathrm{~dB}$ HL for at least one ear, measured by $\mathrm{ABR}$ at 2 years of corrected age. Of these VPT infants, $5(6 \%)$ had SNHL. Proven sepsis was found in $4(80 \%)$ VPT infants with SNHL compared to 23 $(32 \%)$ VPT infants without SNHL $(\mathrm{P}<0.05)$.

Conclusions SNHL could be identified in 6\% of 2-year-old VPT infants in spite of normal NHS shortly after birth. Follow-up audiometric testing after normal NHS is recommended for VPT infants who had proven sepsis in the neonatal period.

\section{INCIDENCE, MORTALITY, MORBIDITY AND COSTS OF LATE PRETERM BIRTHS}

doi:10.1136/archdischild-2012-302724.1218

${ }^{1} \mathrm{C}$ Bulut, 'T Gürsoy, ${ }^{2} \mathrm{~F}$ Ovalı. 'Zeynep Kamil Maternity and Childrens' Disease Training and Research State Hospital; 'Zeynep Kamil Maternity and Childrens' Disease Training and Research State Hospital, Istanbul, Turkey

Background and Aims Since 2005, babies born between 34 0/7 weeks and 36 6/7 weeks are defined as late preterm babies. We aimed to investigate the rates of mortality and morbidity of late preterm babies born at our hospital and compare them with babies born atterm.

Material and Methods A retrospective chart analysis was performed on babies born at our hospital between 2006 and 2008 Demographic features, complications and mortalities were recorded. Results During 3 years, 41752 babies were delivered in our hospital $6742(16.2 \%)$ of them were late preterm and $30055(71.9 \%)$ were term babies. The rate of hospitalizations ( $6.5 \%$ vs $17.5 \%)$, mortality ( $3.6 \%$ vs. $5 \%$ ) and duration of hospitalizations (4 days vs 7 days mean) were significantly higher in the late preterm group. $66 \%$ of late preterm infants were transferred to other units for various reasons. When stratified according to gestational age, there were no significant differences in terms of mortality and morbidity among the subgroups. However, the duration of hospitalizations and the costs of babies born at 34 weeks were significantly higher than those of other babies.

Conclusion Late preterm babies have increased rates of mortality and morbidity, including higher costs, hence constitute an important risk group, which need to be followed up regularly. The mortality and morbidity rates did not appear to increase with decreasing gestational age in late preterm babies but the duration of hospitalization and the costs were higher in babies born at 34 weeks.

\section{DIFFERENCES IN MORTALITY/MORBIDITY WITH A COMPLETE COURSE OF ANTENATAL STEROIDS COMPARED TO AN INCOMPLETE/NO COURSE IN EXTREMELY PREMATURE NEONATES}

doi:10.1136/archdischild-2012-302724.1219

'D Wong, 1,2ME Abdel-Latif, ${ }^{1,2} \mathrm{AL}$ Kent. ${ }^{1}$ Australian National University, Medical School; ${ }^{2}$ Dept of Neonatology, Canberra Hospital, Canberra, ACT, Australia

Background Antenatal steroids have been shown to reduce mortality and morbidity in neonates born less than 29 weeks gestation. Counselling of parents regarding outcomes is generally based on data that includes all neonates whether they have received a complete course of antenatal steroids or not. In the acute setting where delivery is imminent more accurate estimation of outcomes for parents is required.

Aims To determine the differences in survival, short and long term morbidity for those neonates receiving no antenatal steroids or an incomplete course of steroids in comparison to those receiving a complete course.

Methods A retrospective review of prospectively collected data from 10 NICU'S between January 1998 to December 2004

Results 2549 neonates were included in the study with 319 $(12.5 \%)$ not given any ante-natal steroids. Hospital mortality was significantly worse without steroids $(30 \%$ versus $20 \% \mathrm{p}<0.001)$. Those with no steroid coverage were more likely to have NEC $(11 \%$ vs $7 \%$; $p=0.018)$ and Grade 3 or 4 IVH ( $19 \%$ vs $12 \%$; $p=0.001)$. In a multivariate model, factors predictive of mortality included: lack of antenatal steroids, male gender, smaller gestation and hypertensive disease of pregnancy.

Long-term data was available for 1473 survivors. There was no difference in long term neurological outcome between those not receiving steroids and those receiving any steroids. 